\title{
Weight loss intervention adherence and factors promoting adherence: a meta-analysis
}

\author{
This article was published in the following Dove Press journal: \\ Patient Preference and Adherence \\ 12 August 2016 \\ Number of times this article has been viewed
}

\section{Mark Lemstra' \\ Yelena Bird² \\ Chijioke Nwankwo ${ }^{2}$ \\ Marla Rogers ${ }^{3}$ \\ John Moraros ${ }^{2}$} Moose Jaw, ${ }^{2}$ School of Public Health, ${ }^{3}$ College of Medicine, University of Saskatchewan, Saskatoon, SK, Canada

Correspondence: Mark Lemstra Alliance Wellness \& Rehabilitation B70 500 - Ist Ave NW Moose Jaw, SK S6H 3M5 Canada Email marklemstra@shaw.ca
'Alliance Wellness and Rehabilitation,

Background: Adhering to weight loss interventions is difficult for many people. The majority of those who are overweight or obese and attempt to lose weight are simply not successful. The objectives of this study were 1) to quantify overall adherence rates for various weight loss interventions and 2) to provide pooled estimates for factors associated with improved adherence to weight loss interventions.

Methods: We performed a systematic literature review and meta-analysis of all studies published between January 2004 and August 2015 that reviewed weight loss intervention adherence.

Results: After applying inclusion and exclusion criteria and checking the methodological quality, 27 studies were included in the meta-analysis. The overall adherence rate was $60.5 \%$ (95\% confidence interval [CI] 53.6-67.2). The following three main variables were found to impact adherence: 1) supervised attendance programs had higher adherence rates than those with no supervision (rate ratio [RR] 1.65; 95\% CI 1.54-1.77); 2) interventions that offered social support had higher adherence than those without social support (RR 1.29; 95\% CI 1.24-1.34); and 3) dietary intervention alone had higher adherence than exercise programs alone (RR 1.27; 95\% CI 1.19-1.35).

Conclusion: A substantial proportion of people do not adhere to weight loss interventions. Programs supervising attendance, offering social support, and focusing on dietary modification have better adherence than interventions not supervising attendance, not offering social support, and focusing exclusively on exercise.

Keywords: community based, obesity, social support, program adherence

\section{Introduction}

Obesity is a common chronic condition that increases the risk of numerous health problems, including cardiovascular diseases, diabetes, cancer, and mental health issues. ${ }^{1}$ Substantial weight loss is not required to start to see health benefits. For example, a 5\% reduction in body weight is enough to improve health outcomes. ${ }^{1}$ According to data from the 1998 National Health Interview Survey, 50\% of obese men and 58\% of obese women in the US are actively trying to lose weight. ${ }^{2}$ Regrettably, despite the efforts of a large portion of the population, the prevalence of obesity has remained high. ${ }^{3}$

It is especially difficult to lose weight among those suffering from obesity, as it is a complex condition created by diverse genetic, environmental, cultural, and socioeconomic pathways. For example, a recent study concluded that the chances of returning to a normal weight for someone who is already obese are extremely low: one in 210 chances for men and one in 124 chances for women. ${ }^{4}$ According to the National Health Interview Study mentioned earlier, the most commonly reported weight loss methods are as follows: 1) calorie restriction alone, 2) eating less fat, and 3 ) exercising more. ${ }^{2}$

All of that said, moderate weight loss for health reasons is possible, even among those who are obese. For example, a study of 4,034 obese adults in the US found that 
$40 \%$ lost $>5 \%$ of their body weight in the past year and $20 \%$ lost $>10 \%{ }^{5}$ However, participants need to adhere to evidence-based weight loss methods to lose weight and maintain weight loss in the long term. A meta-analysis of 18 randomized controlled trials (RCTs) found that diet and exercise programs combined were clearly superior to diet programs alone or exercise programs alone. ${ }^{6}$ A meta-analysis of 29 studies looking at long-term ( 5 years) weight loss maintenance among those who participated in structured weight loss programs, found that the average individual maintained at least $3 \mathrm{~kg}$ of weight loss and at least a $3 \%$ reduction of initial body weight. The authors found that those who lost more weight prior to starting the programs were more likely to keep weight off and those who exercised more were able to better maintain their weight loss than those who did not. ${ }^{7}$

Adhering to healthy weight loss behaviors is required for weight loss initially and in the long term. If participants are unable to adhere to weight loss strategies, they will not lose weight. Problems with attrition and nonadherence exist for intervention programs that are often evaluated in the short term. For example, a meta-analysis of 80 studies on weight loss interventions with a control group found a mean attrition rate of $31 \%{ }^{8}$ In a meta-analysis of 45 RCTs of nonsurgical weight loss interventions in obese adults, it was found that $28.4 \%$ of participants dropped out of the study prior to the maintenance phase and that many of these dropouts were due to not meeting adherence criteria or weight loss criteria during the study phase. ${ }^{9}$

An important part of advancing weight loss interventions is to understand how to improve adherence to weight loss behaviors. In any health behavior, nonadherence is a problem. The World Health Organization has identified nonadherence as a problem, "of striking magnitude". ${ }^{10}$ Behavior change is complex, and even in life-threatening situations, it is difficult for people to adhere to medical advice. For example, a report from Statistics Canada found that among smokers with new diagnoses of chronic diseases: $75 \%$ of patients with a recent diagnosis of heart disease, $78 \%$ of those with a new cancer diagnosis, $74 \%$ of those with stroke, and $96 \%$ of those with respiratory disease did not quit smoking. ${ }^{11}$ Concerning weight-related health risks, more optimistic results have been reported about behavioral changes. For example, a study of 600 participants with a new diagnosis of type II diabetes found that only 20 people were able to change all their cardiovascular disease risk behaviors within 1 year, but many were able to decrease their Body Mass Index (BMI) and decrease their total daily calorie intake. ${ }^{12}$

In regard to weight loss interventions among those with obesity, there have been no meta-analyses investigating factors that improve adherence rates. The objective of this review and meta-analysis was to quantify adherence rates for various weight loss intervention types and to provide pooled estimates for factors associated with improved adherence to weight loss interventions.

\section{Methods}

A systematic literature review was performed, accessing the following databases: Medline, PubMed, ProQuest, CINAHL, Cochrane Central, Global Health, ISI Web of Knowledge, ProQuest, SCOPUS, and EMBASE. Search dates ranged from January 2004 to August 2015.

Subject search descriptors included terms listed in Figure 1. Search terms included relevant weight loss or reduction interventions and adherence or behavior modification (Supplementary material). Adherence was defined as completion of the weight loss program or, in certain cases, was assessed by the level of consistency with the weight loss intervention of interest. Reference sections of each article were reviewed for additional articles. Unpublished articles were not included in our search.

The following inclusion criteria were used in the search:

1. Article should clearly describe adherence to a weight loss program, and the said program should be neither pharmacological nor surgical.

2. Article should have quantifiable data describing the effect size (ie, some absolute or relative measure of program adherence).

3. Article should describe a study that is prospective in nature (ie, an RCT, a quasiexperimental, or a cohort study).

4. Article should be publicly available.

5. Article should be published in the English language.

The search strategies excluded opinion articles, letters to the editor, case reports, and case studies.

Titles were initially reviewed for relevance and to remove duplication. The articles that remained were then subjected to full abstract review in order to apply inclusion and exclusion criteria. Finally, the remaining articles were subjected to full review and methodological quality evaluation by a panel of two reviewers (CN and $\mathrm{ML}$ ). Unanimous agreement was sought; however, when there was disagreement, a tie breaker was used with a third author (JM).

We used methodological quality checklists for experimental and quasiexperimental designs from Greenhalgh et al. ${ }^{13}$ These checklists are a validated modification of the Cochrane Effective Practice and Organization of Care checklist and contain ten questions covering six areas of 


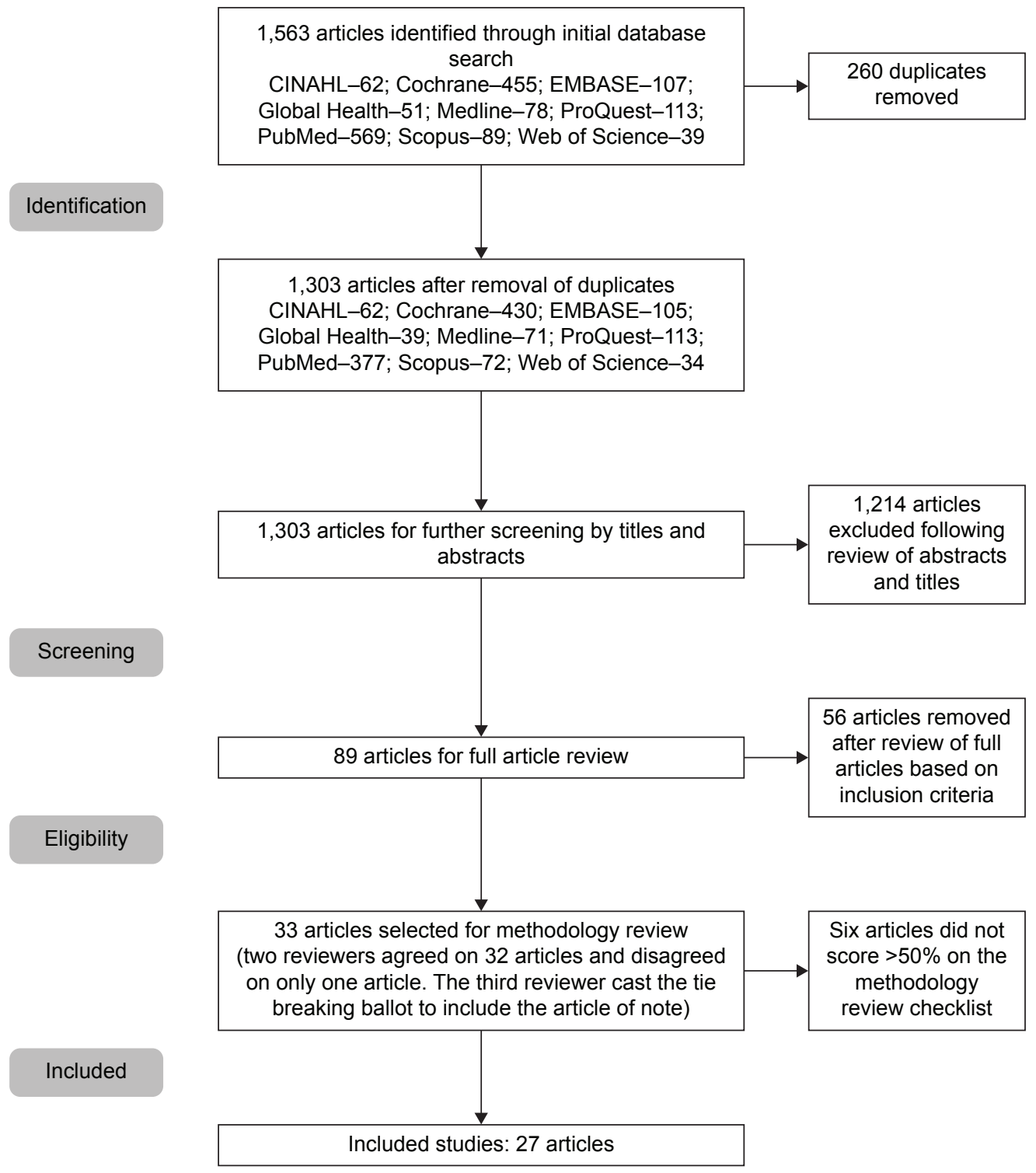

Figure I Flow diagram for included studies.

methodological rigor (eleven questions for quasiexperimental designs). The lists made provisions for assessing bias with the different study designs. A score of six was required in order to be accepted for review (ie, a score $>50 \%$ ). ${ }^{14,15}$ The checklists are presented in Tables 1 and 2 .

A computer program that utilized a random effects model, taken from Fleiss, ${ }^{16}$ was built to take interstudy heterogeneity into account. The statistical basis and its assumptions have been previously described in detail elsewhere. ${ }^{17-19}$ At least four articles were required for statistical pooling.

\section{Results}

\section{Systematic review}

The initial search generated 1,563 articles of which 260 articles were duplicates and removed, leaving 1,303 articles to screen abstracts. After the initial screening, 89 articles were included in the full review with 56 articles removed based on the inclusion/exclusion criteria. The remaining 33 articles were then subjected to full methodological review by two reviewers. There was disagreement on only one article that was included based on tie-breaking vote from a third reviewer. In total, six of the articles did not meet methodological requirements, leaving 27 articles for metaanalysis. Figure 1 depicts the search process. Studies included in the analysis and their detailed results are presented in Table $3 .^{20-46}$

\section{Operationalizing adherence}

Intervention adherence ranged significantly from $10 \%{ }^{20}$ to $99.5 \% .^{29}$ Adherence was operationalized in 13 studies, 
Table I Methodology checklist for experimental designs

\begin{tabular}{ll}
\hline Authors: & \\
\hline Study title: & \\
\hline
\end{tabular}

A. Research question and design

I. Was there a clear research question and was this important and sensible?

2. If the study was nonrandomized, could a randomized controlled design have been used?

B. Baseline comparability of groups

3. [RCTs only]: Was allocation adequately concealed by a rigorous method (eg, random number)?

4. Were appropriate measures of baseline characteristics taken in all groups before the intervention and were study groups shown to be comparable in all characteristics likely to influence outcome?

C. Outcome measures

5. Was the primary outcome measure valid (ie, do two independent raters agree that this was a sensible and reasonable measure of performance or outcome)?

6. Was the primary outcome measure reliable (ie, do two independent raters agree on the nature and extent of change)?

D. Protection against contamination

7. Is it unlikely that the control unit of allocation (professional, practice, institution, and community) received the intervention through contamination?

E. Protection against bias

8. Were outcomes measured by "blinded" observers or were they objectively verified (eg, quantitative measures recorded prospectively and independently)?

\section{F. Follow-up}

9. Was there complete follow-up of participants (ideally $>80 \%$ )

10. Was follow-up continued for long enough for the primary outcome measure to show an impact and for sustainability to be demonstrated?

Note: Passing score for experimental designs $=6 / 10$.

Abbreviation: RCT, randomized controlled trial.

Table 2 Quasiexperimental designs

\begin{tabular}{lll}
\hline Authors: & \\
\hline Study title: & Yes & No \\
\hline
\end{tabular}

\section{A. Research question and design}

I. Was there a clear research question, and was this important and sensible?

2. If the study was nonrandomized, could a randomized controlled design have been used?

B. Protection against secular changes

3. Was the intervention independent of other changes over time?

4. Were there sufficient data points to enable reliable statistical inference?

5. Was a formal statistical test for trend correctly undertaken?

\section{Outcome measures}

6. Was the primary outcome measure valid (ie, do two independent raters agree that this was a sensible and reasonable measure of performance or outcome)?

7. Was the primary outcome measure reliable (ie, do two independent raters agree on the nature and extent of change)?

\section{Protection against detection bias}

8. Was the intervention unlikely to affect data collection (eg, sources and methods of data collection were the same before and after the intervention)?

9. Were outcomes measured by "blinded" observers or were they objectively verified (eg, quantitative measures recorded prospectively and independently)?

F. Completeness of data set and follow-up

10. Does the data set cover all or most of the episodes of care (or other unit of analysis) covered by the study (ideally $>80 \%$ )?

II. Was follow-up continued for long enough for the primary outcome measure to show an impact and for sustainability to be demonstrated?

Note: Passing score for quasiexperimental designs $=6 / 1 \mathrm{l}$. 


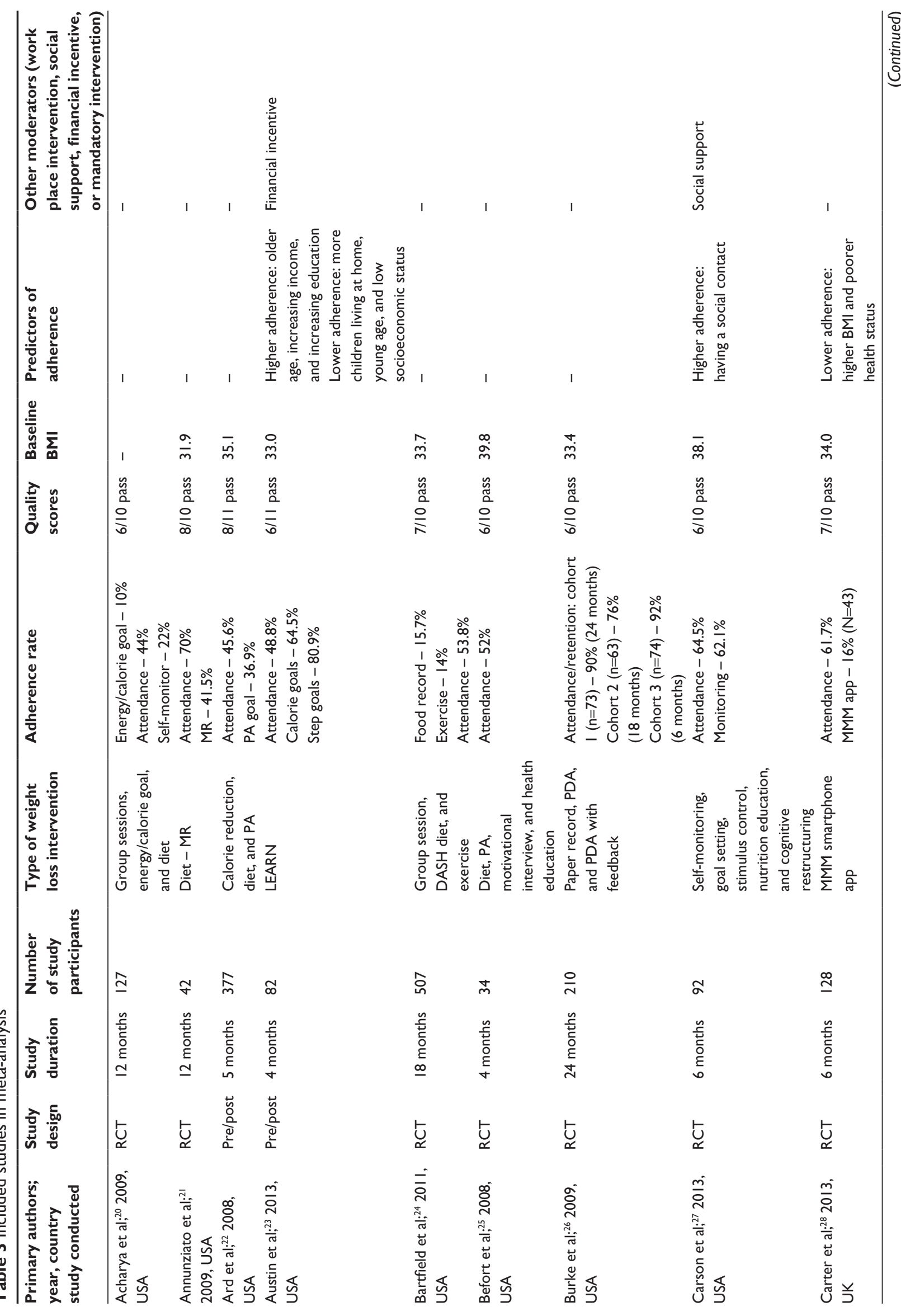




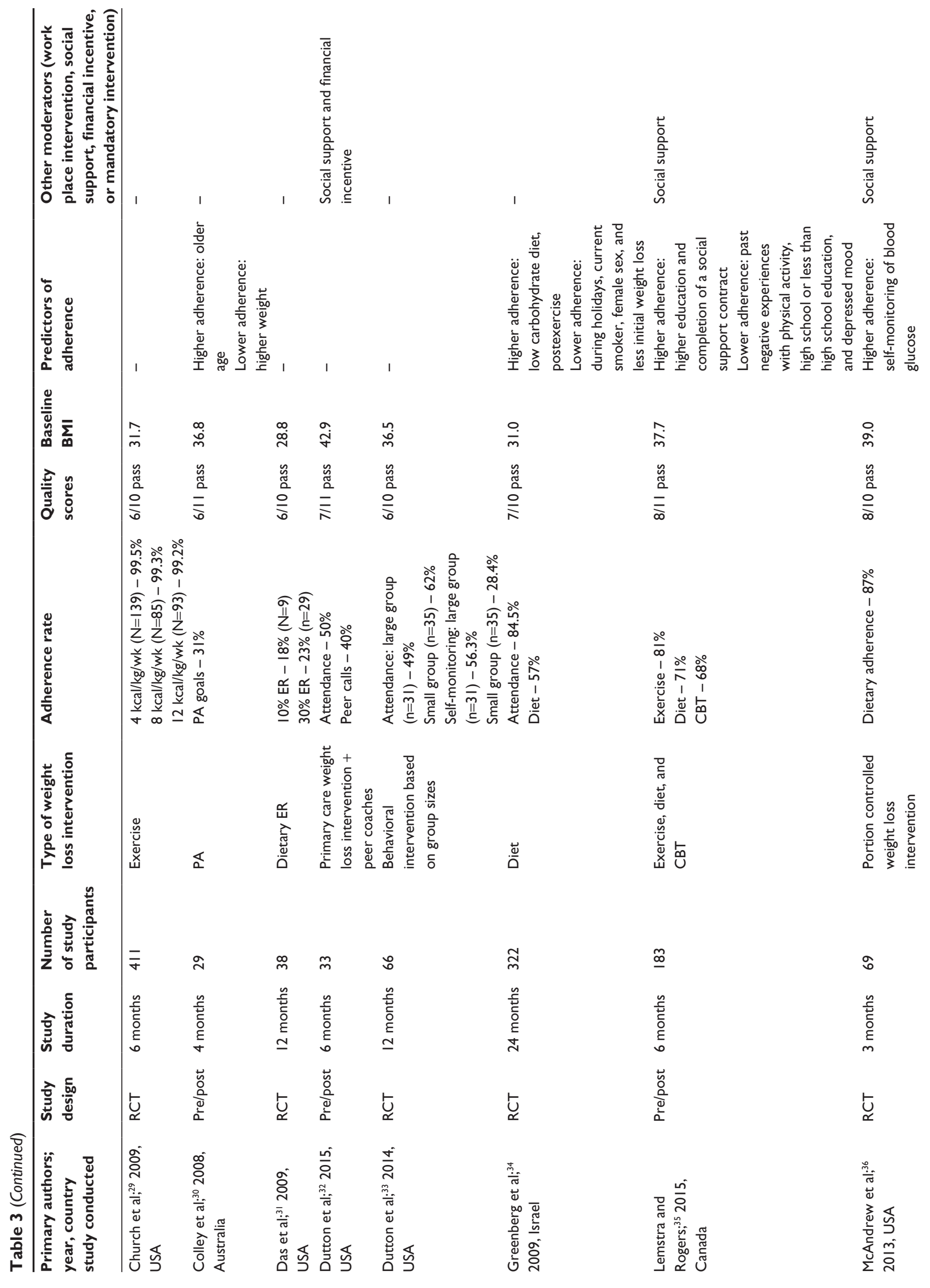




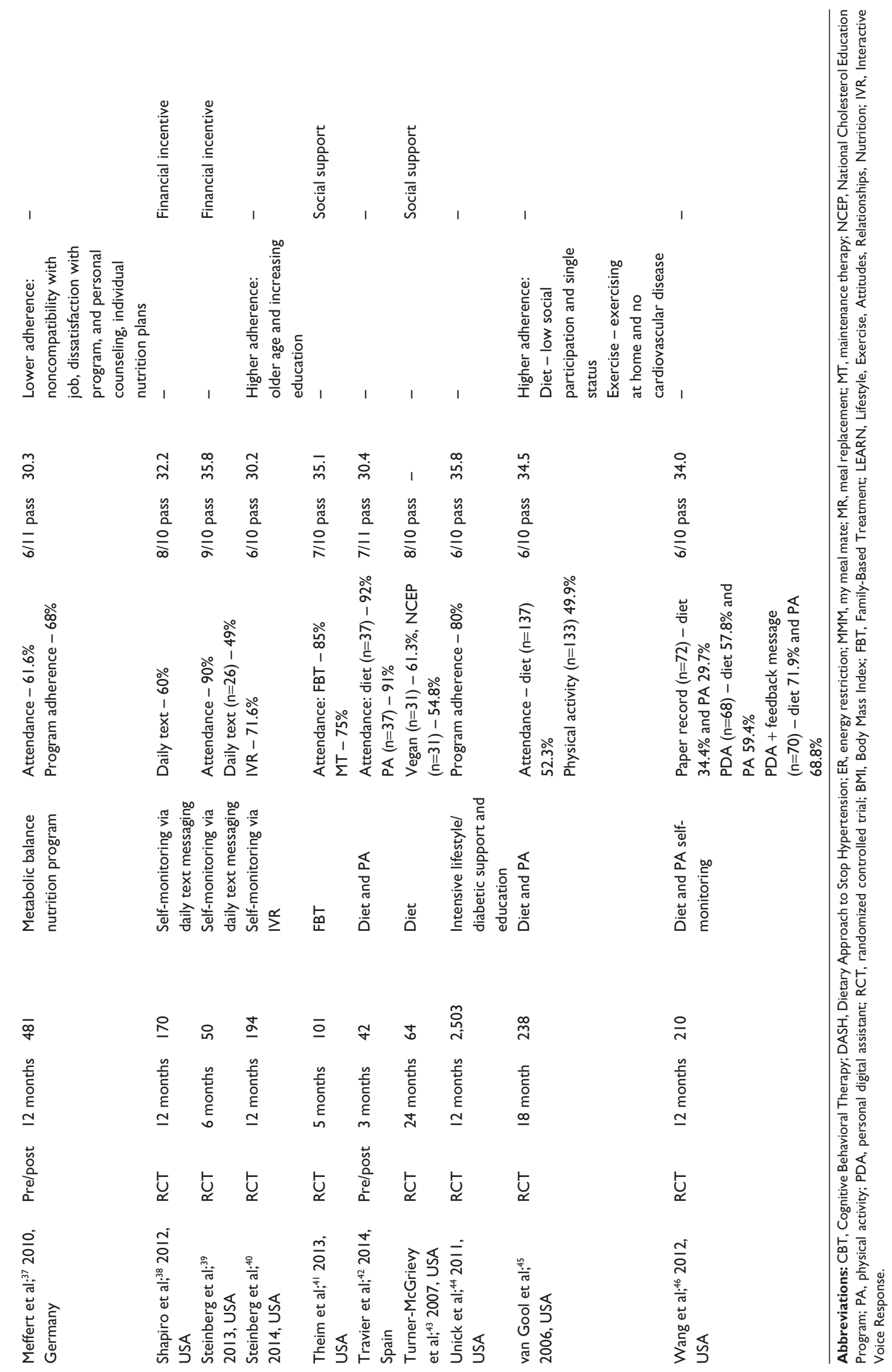


Table 4 Adherence rate and rate ratio for multifactor subgroup analysis across baseline body mass index, study duration, financial incentive, social support, age, study design, and intervention type

\begin{tabular}{|c|c|c|c|c|c|c|c|c|}
\hline Factor & Subgroup I & $\mathbf{N}$ & $\begin{array}{l}\text { Adherent } \\
\text { (\%) }\end{array}$ & Subgroup 2 & $\mathbf{N}$ & $\begin{array}{l}\text { Adherent } \\
\text { (\%) }\end{array}$ & $\begin{array}{l}\text { Adherence rate } \\
\text { ratio (I vs } 2 \text { ) }\end{array}$ & $95 \% \mathrm{Cl}$ \\
\hline Baseline BMI & Overweight/moderate obesity & 5,321 & 63.39 & Severe/morbid obesity & 4,598 & 61.56 & 1.03 & $1.00-1.06$ \\
\hline Study duration & $<12$ months & 2,771 & 69.88 & $\geq 12$ months & 7,591 & 53.01 & 1.32 & $1.28-1.36$ \\
\hline Financial incentive & Financial incentive & 538 & 61.79 & No financial incentive & 9,804 & 60.33 & 1.02 & $0.96-1.10$ \\
\hline Social support & Social support & $\mathrm{I}, 144$ & 73.43 & No social support & 9,218 & 57.11 & 1.29 & $1.24-1.34$ \\
\hline Age & Predicted by older age & 469 & 60.97 & Not predicted by older age & 9,893 & 60.50 & 1.01 & $0.94-1.09$ \\
\hline Study design & $\mathrm{RCT}$ & 2,680 & 63.05 & Pre/post & 7,682 & 59.57 & 1.06 & $1.02-1.10$ \\
\hline \multirow[t]{6}{*}{ Intervention type } & Supervised program & 5,600 & 68.59 & Diet & 1,933 & 63.73 & 1.08 & $1.04-1.12$ \\
\hline & PA & 1,388 & 50.21 & Self-monitoring & 1,258 & 41.50 & 1.21 & $1.11-1.32$ \\
\hline & Supervised program & 5,600 & 68.59 & Self-monitoring & 1,258 & 41.50 & 1.65 & I.54-I.77 \\
\hline & Diet & 1,933 & 63.73 & PA & I,388 & 50.21 & 1.27 & $1.19-1.35$ \\
\hline & Supervised program & 5,600 & 68.59 & PA & $\mathrm{I}, 388$ & 50.21 & 1.37 & $1.29-1.44$ \\
\hline & Diet & 1,933 & 63.73 & Self-monitoring & $\mathrm{I}, 258$ & 41.50 & 1.54 & $1.43-1.65$ \\
\hline
\end{tabular}

Notes: Potential moderators of exercise adherence were identified apriori and used as factors for a subgroup analysis. Subgroup I and 2 were used (for analytical purposes) to represent the sub-categories within each pre-determined factor. Adherence rates were estimated for each sub-category (subgroup) of the pre-determined factors. The adherence rates for each subgroup represents the pooled estimate for a particular sub-category of a given factor. Pairwise rate ratios were computed for all sub-categories of each factor. "Supervised program" and "Self-monitoring" as used above, refer to whether the participants were directly monitored by the investigators or not, respectively. Subgroup analysis by intervention type aims to determine which of supervised monitoring, self monitoring, diet alone, or physical activity alone had a greater effect on adherence to weight loss programs. Abbreviations: $\mathrm{N}$, number of participants in subgroup; PA, physical activity; $\mathrm{RCT}$, randomized controlled trial; $\mathrm{Cl}$, confidence interval.

where threshold rates were given to determine adherence to particular intervention behaviors. ${ }^{20,22-24,29-32,34,35,37,38,43}$

\section{Study design}

Twenty of the articles were RCTs with 5,576 participants (ranging from 34 to 2,503). The remaining seven articles were observational intervention studies with 1,227 participants (ranging from 29 to 481), for a total of 6,803 participants included in the overall analysis. Among RCTs, the mean adherence was $63.1 \%$, while the mean adherence for the observational intervention studies was $59.6 \%$.

\section{Study length of time and adherence}

The duration of nine of the studies was 12 months, with a sample size of 3,831 participants. ${ }^{20,21,31,33,37,38,40,44,46}$ The duration of 13 studies was $<12$ months with a sample size of 1,631 participants, ${ }^{22,23,25,27-30,32,35,36,39,41,42}$ and the duration of five studies was $\geq 18$ months with a sample size of 1,341 participants ${ }^{24,26,34,43,45}$ (no articles had study durations between 12 months and 18 months). Interventions lasting $<12$ months had a mean adherence rate of $69.9 \%$, while those lasting $\geq 12$ months had a mean adherence rate of $53.0 \%$.

\section{Factors that affect adherence}

Only ten of the 27 studies discussed factors that affected adherence. ${ }^{23,27,28,30,34-37,40,45}$ One study ${ }^{23}$ found associations between higher adherence and older age, higher income, and higher education. Older age was also associated with better adherence in two other studies, ${ }^{30,40}$ and increasing education levels were associated with higher adherence in two other studies. ${ }^{35,40}$ Social support contracts increased adherence rates in two studies ${ }^{27,35}$ and six studies in total, including a social support aspect to the intervention. . $7,32,35,36,41,43^{2}$

Six studies discussed factors associated with lower adherence. ${ }^{23,28,30,34,35,37}$ These included lower socioeconomic status (education and income), ${ }^{23,35}$ higher weight, ${ }^{28,30}$ poor health ${ }^{28}$ dissatisfaction with the program or weight loss results, ${ }^{34,37}$ smoking status, ${ }^{34}$ and depressed mood..$^{35}$

\section{Subgroup analysis}

Subgroup analysis is presented in Table 4. Interventions with a duration of $<12$ months had higher adherence rates than interventions lasting $\geq 12$ months (RR $1.32 ; 95 \% \mathrm{CI}$ 1.28-1.36). Those interventions that included social support improved adherence rates by $29 \%$ compared to those interventions that did not include social support (95\% CI 1.24-1.34).

Self-monitoring programs had the lowest adherence rate $(41.5 \%)$, and supervised interventions had the highest adherence rate $(68.6 \%)$. When attendance was monitored (supervised) by a researcher or intervention leader, participants were more adherent compared to programs that used selfmonitoring interventions (RR 1.65; 95\% CI 1.54-1.77), diet interventions, or physical activity interventions without supervision or attendance tracking. Participants were more adherent to diet interventions alone than exercise interventions alone (RR 1.27; 95\% CI 1.19-1.35) or self-monitoring interventions (RR 1.54; 95\% CI 1.43-1.65).

\section{Interpretation}

It is not possible to lose weight without actually adhering to weight loss protocols, such as exercise and dietary 
interventions. In weight loss interventions, nonadherence rates are usually high. In this article, we have included studies with interventions using methods, such as education, self-monitoring (electronic or nonelectronic), group-based or individual exercise or diet interventions, peer support, and lifestyle interventions, which included both diet and exercise. For many studies, adherence rates were low; as low as $10 \%$ in a 12 -month study. ${ }^{20}$ Different intervention strategies reported various adherence rates within different study designs. We performed a pooled subgroup analysis to determine intervention characteristics that increase the likelihood of participant adherence.

High adherence rates were observed for interventions that incorporated aspects of social support. Social support is an important determinant in overall health. The Public Health Agency of Canada has listed social support as the second most important determinant of health, ${ }^{47}$ and the results from a number of studies indicate that those with social supports in place even have a reduced risk of premature mortality. ${ }^{48-50}$

Social support in the studies reviewed in this article ranged from group sessions to peer coaches to social support contracts to "buddy" programs. In the existing literature, multiple studies have indicated that social support (whether through family, friends, peers, or providers) is important for successful behavioral change. For example, one study found that those who received guided support for weight loss were $37 \%$ more likely to maintain weight loss than those who participated in self-directed strategies. ${ }^{51}$

Participation in weight loss interventions that allow friends or family to participate may have important implications for weight loss and weight loss maintenance. A previous study compared a weight loss intervention in which participants attended alone, with three friends, or with family members and found that at 6-month follow-up, those who attended with family or friends were more likely to maintain weight loss after program completion than those who attended alone. ${ }^{52}$ Social support contracts also allow ongoing support outside of the program. These contracts can help maintain a stronger commitment to a weight loss plan and have been shown to also improve rates of weight loss when compared to those who try to lose weight on their own. ${ }^{53}$ As such, it is important to incorporate aspects of social support into weight loss interventions and to provide social support when participants have none. Utilizing existing social networks may be one way to do this, while using existing technology to deliver social support via the web or smartphones is another. These social tools may also act as a motivational tool for participants to remain engaged in the weight loss intervention. ${ }^{54}$
Our analysis also determined that programs supervising and monitoring attendance improved adherence rates by $65 \%$ compared to self-monitoring programs and had the highest adherence rates overall. Monitoring attendance likely improves adherence rates since participants are more accountable for their behaviors. Supervision has been found to increase physical activity intervention adherence in other conditions. For example, a mixed methodology study on adherence to a physical activity program in patients with chronic obstructive pulmonary disorder found that participants felt that they would not be able to maintain the behaviors if not for the group dynamic of the classes and the required reporting to the physiotherapist. ${ }^{55}$

Supervised programs also allow participants to access health-care provider knowledge and feedback. Working without guidance can be discouraging and, at times, dangerous. Increasing knowledge transfer through access to an expert supervisor may help improve self-efficacy. ${ }^{56}$ Furthermore, a good relationship between supervisors and participants can increase adherence to additional health advice. ${ }^{56}$

Better adherence was also seen when comparing randomized with nonrandomized studies. This result has been observed in other health intervention studies, including a meta-analysis on adherence to statin therapy, where $90 \%$ of patients in RCTs were adherent to statin therapy, while only $49 \%$ were adherent in observational studies. ${ }^{57}$ This may be attributed in large part to the structured and specific nature of the inclusion and exclusion criteria used in RCTs. As such, participants in RCTs tend to be "less sick, younger, better educated, and of higher socioeconomic status". ${ }^{58}$ It has been estimated that the average RCT excludes $90 \%$ of patients. ${ }^{59}$ There are other key differences in RCTs when compared to observational studies that could improve adherence, including differences in patient populations, different intervention intensities or therapeutic regimens, control of confounding factors, potentially more rigorous follow-up, among others. ${ }^{60}$ Additionally, due to the funding structure of RCTs and their need to evaluate efficacy instead of realworld effectiveness, these studies tend to be more heavily supervised. As such, the finding that randomized trials have higher adherence than observational studies is likely due to supervised programming and the recruitment of more "ideal" participants. For those offering clinical weight loss interventions, it is important to have participants engage in activities in which they are held accountable for their attendance or adherence to a group, a care provider, or a social support individual.

We also found better adherence to dietary interventions alone than exercise interventions alone. This could be due 
to a number of reasons. First, in cases where diet adherence was captured via self-report, poor recall or false information could be a possibility. ${ }^{61}$ Second, it may be due in part to participants seeing more weight loss from restrictive diets than from exercise interventions, which is supported by the literature. ${ }^{6,62}$ However, it has been previously stated that dietary and exercise programming needs to be combined in order to be most effective. ${ }^{6,62}$ Physical activity is important to overall health and overall weight loss maintenance ${ }^{63}$ and should be encouraged as a part of a weight loss intervention along with dietary change.

Financial incentives for weight loss programs are discussed throughout the literature, and four studies were included in our analysis..$^{23,32,38,39}$ However, when comparing interventions that utilized financial incentives with those studies that did not, there were no significant differences in adherence rates. Among the studies using financial incentives, the participant pool was among the smallest in our analysis.

\section{Future research}

Weight loss intervention studies targeting obese individuals should take into account and measure factors that predict adherence. Few studies were found in this systematic review that had acceptable methodological rigor. Given the high prevalence of obesity and the importance of adherence in order to lose weight and maintain weight loss, this is an important area to continue to study.

\section{Study limitations}

Due to the variability between studies, the pooling of data, while helpful in increasing the sample size, does introduce a level of uncertainty, with regard to the study conclusion due to possible sampling errors or unmeasured covariates. Also, there were only ten studies in which the authors set out to measure factors that predict adherence to weight loss programs. Therefore, it is possible that the remaining studies may not have given proper consideration to potential confounders for adherence or made the necessary adjustment as needed.

\section{Conclusion}

It is unlikely that there is a single solution to reverse the rising prevalence of obesity observed globally. A comprehensive approach is needed to address this complex issue. Supervising weight loss programs and adding social supports help improve adherence to weight loss programs. It is expected that with better adherence, overweight or obese persons can lose more weight and help keep it off in the long term. Evaluating the views of participants and adherence rates to weight loss programs is critical as it can offer insight, expand our current knowledge, and provide evidence in support of designing and implementing more effective interventions.

\section{Disclosure}

The authors report no conflicts of interest in this work.

\section{References}

1. National Institutes of Health. Clinical Guidelines on the Identification, Evaluation, and Treatment of Overweight and Obesity in Adults: The Evidence Report. Bethesda, MD: National Institutes of Health; 1998. NIH Publication No. 98-4083.

2. Kruger J, Galusk DA, Serdula MK, Jones DA. Attempting to lose weight: specific practices among U.S. adults. Am J Prev Med. 2004;26(5): 402-406.

3. Ogden CL, Carroll MD, Kit BK, Flegal KM. Prevalence of childhood and adult obesity in the United States, 2011-2012. JAMA. 2014; 311(8):806-814.

4. Fildes A, Charlton J, Rudisill C, Littlejohns T, Gulliford MC, Prevost AT. Probability of an obese person attaining normal body weight: cohort study using electronic health records. Am J Pub Health. 2015;105(9): e54-e59.

5. Nicklas JM, Huskey K, Davis RB, Wee CC. Successful weight loss among obese U.S. adults. Am J Prev Med. 2012;42(5):481-485.

6. Wu T, Gao X, Chen M, van Dam RM. Long-term effectiveness of diet-plus-exercise interventions vs diet-only interventions for weight loss: a meta-analysis. Obes Rev. 2009;10(3):313-323.

7. Anderson JW, Konz EC, Frederich RC, Wood CL. Long-term weightloss maintenance: a meta-analysis of US studies. Am J Clin Nutr. 2001; 74(5):579-584.

8. Franz MJ, van Wormer JJ, Crain AL, et al. Weight-loss outcomes: systematic review and meta-analysis of weight-loss clinical trials with a minimum 1-year follow-up. J Am Diet Assoc. 2007;107(10): 1755-1767.

9. Dombrowski SU, Knittle K, Avenell A, Araujo-Soares V, Sniehotta FF. Long-term maintenance of weight loss with non-surgical interventions in obese adults: systematic review and meta-analyses of randomised controlled trials. BMJ. 2014;348:g2646.

10. World Health Organization [webpage on the Internet]. Adherence to Long-Term Therapies. Evidence for Action. Geneva: World Health Organization; 2003. Available from: http://whqlibdoc.who.int/ publications/2003/9241545992.pdf. Accessed April 22, 2016.

11. Statistics Canada [webpage on the Internet]. Health Behaviour Changes After Diagnosis of Chronic Illness Among Canadians Aged 50 or Olde; 2012). Available from: http://www.statcan.gc.ca/pub/82-003x/2012004/article/11740-eng.pdf. Accessed April 22, 2016.

12. Long GH, Cooper AJM, Wareham NJ, Griffin SJ, Simmons RK. Healthy behavior change and cardiovascular outcomes in newly diagnosed Type 2 diabetic patients: a cohort analysis of the ADDITIONCambridge study. Diabetes Care. 2014;37(6):1712-1720.

13. Greenhalgh T, Robert G, Bate P, et al. Diffusion of Innovations in Health Service Organizations: A Systematic Literature Review. Malden, MA: Blackwell Publishing Ltd.; 2005.

14. Lemstra M, Alsabbagh MW. Proportion and risk indicators of nonadherence to antihypertensive therapy: a meta-analysis. Patient Prefer Adherence. 2014;8:211-218.

15. Alsabbagh W, Lemstra M, Eurich D, et al [webpage on the Internet]. Socioeconomic Status and Non Adherence to Anti-Hypertensive Drugs: A Systematic Review and Meta-Analysis. Value in Health; 2014. Available from: http://www.ispor.org/publications/value/articlesinpress.asp. Accessed April 22, 2016. 
16. Fleiss JL. The statistical basis of meta-analysis. Stat Methods Med Res. 1993;2(2):121-145.

17. Lemstra M, Bennett N, Neudorf C, et al. A meta-analysis of school based marijuana and alcohol prevention programs in targeting adolescents aged 10-15 years old. Addict Res Theory. 2010;18(1):84-96.

18. Lemstra M, Bennett N, Neudorf C, et al. A systematic review of drug and alcohol use by socioeconomic status in adolescents aged $10-15$ years. Can J Pub Health. 2008;99(3):172-177.

19. Lemstra M, Neudorf C, D’Arcy C, Kunst A, Warren L, Bennett N. A systematic review of depressed mood and anxiety by socioeconomic status in adolescents aged 10-15 years. Can J Pub Health. 2008;99(2): 125-129.

20. Acharya S, Elci O, Sereika S, et al. Adherence to a behavioral weight loss treatment program enhances weight loss and improvements in biomarkers. Patient Prefer Adherence. 2009;3:151-160.

21. Annunziato R, Timko C, Crerand C, et al. A randomized trial examining differential meal replacement adherence in a weight loss maintenance program after one-year follow-up. Eat Behav. 2009;10(3) $176-183$.

22. Ard J, Kumanyika S, Stevens V, et al. Effect of group racial composition on weight loss in African Americans. Obesity. 2008;16(2):306-310.

23. Austin J, Smith J, Gianini L, Campos-Melady M. Attitudinal familism predicts weight management adherence in Mexican American women. J Behav Med. 2013;36(3):259-269.

24. Bartfield J, Stevens V, Jerome G, et al. Behavioral transitions and weight change patterns within the PREMIER Trial. Obesity. 2011;19(8): 1609-1615.

25. Befort C, Nollen N, Ellerbeck E, Sullivan D, Thomas J, Ahluwalia J. Motivational interviewing fails to improve outcomes of a behavioral weight loss program for obese African American women: a pilot randomized trial. J Behav Med. 2008;31(5):367-377.

26. Burke L, Styn M, Glanz K, et al. SMART trial: a randomized clinical trial of self-monitoring in behavioral weight management-design and baseline findings. Contemp Clin Trials. 2009;30(6):540-551.

27. Carson T, Eddings K, Krukowski R, Love S, Harvey-Berino J, West D. Examining social influence on participation and outcomes among a network of behavioral weight-loss intervention enrollees. JObes. 2013; 2013:1-8.

28. Carter M, Burley V, Nykjaer C, Cade J. Adherence to a smartphone application for weight loss compared to website and paper diary: pilot randomized controlled trial. J Med Internet Res. 2013; 15(4): $\mathrm{e} 32$.

29. Church T, Martin C, Thompson A, Earnest C, Mikus C, Blair S. Changes in weight, waist circumference and compensatory responses with different doses of exercise among sedentary, overweight postmenopausal women. PLoS One. 2009;4(2):e4515.

30. Colley R, Hills A, O’Moore-Sullivan T, Hickman I, Prins J, Byrne N. Variability in adherence to an unsupervised exercise prescription in obese women. Int J Obes Relat Metab Disord. 2008;32(5):837-844.

31. Das S, Saltzman E, Gilhooly C, et al. Low or moderate dietary energy restriction for long-term weight loss: what works best? Obesity. 2009; 17(11):2019-2024

32. Dutton G, Phillips J, Kukkamalla M, Cherrington A, Safford M. Pilot study evaluating the feasibility and initial outcomes of a primary care weight loss intervention with peer coaches. Diabetes Educ. 2015;41(3): 361-368.

33. Dutton G, Nackers L, Dubyak P, et al. A randomized trial comparing weight loss treatment delivered in large versus small groups. Int J Behav Nutr Phys Act. 2014;11(1):123.

34. Greenberg I, Stampfer M, Schwarzfuchs D, Shai I; DIRECT Group. Adherence and success in long-term weight loss diets: the dietary intervention randomized controlled trial (DIRECT). $J$ Am Coll Nutr. 2009;28(2):159-168

35. Lemstra M, Rogers M. The importance of community consultation and social support in adhering to an obesity reduction program: results from the Healthy Weights Initiative. Patient Preference and Adherence. 2015; 9(9): 1473-1480
36. McAndrew L, Napolitano M, Pogach L, et al. The impact of selfmonitoring of blood glucose on a behavioral weight loss intervention for patients with Type 2 diabetes. Diabetes Educ. 2012;39(3):397-405.

37. Meffert C, Gerdes N. Program adherence and efectiveness of a commercial nutrition program: the metabolic balance study. J Nutr Metab. 2010;2010:1-8.

38. Shapiro J, Koro T, Doran N, et al. Text4Diet: a randomized controlled study using text messaging for weight loss behaviors. Prev Med. 2012; 55(5):412-417.

39. Steinberg D, Levine E, Askew S, Foley P, Bennett G. Daily text messaging for weight control among racial and ethnic minority women: randomized controlled pilot study. J Med Internet Res. 2013;15(11): e244.

40. Steinberg D, Levine E, Lane I, et al. Adherence to self-monitoring via interactive voice response technology in an ehealth intervention targeting weight gain prevention among Black women: randomized controlled trial. J Med Internet Res. 2014;16(4):e114.

41. Theim K, Sinton M, Goldschmidt A, et al. Adherence to behavioral targets and treatment attendance during a pediatric weight control trial. Obesity. 2013;21(2):394-397.

42. Travier N, Fonseca-Nunes A, Javierre C, et al. Effect of a diet and physical activity intervention on body weight and nutritional patterns in overweight and obese breast cancer survivors. Med Oncol. 2014; 31(1):783.

43. Turner-McGrievy G, Barnard N, Scialli A. A two-year randomized weight loss trial comparing a vegan diet to a more moderate low-fat diet. Obesity. 2007;15(9):2276-2281.

44. Unick J, Beavers D, Jakicic J, et al. Effectiveness of lifestyle interventions for individuals with severe obesity and Type 2 diabetes: results from the Look AHEAD trial. Diabetes Care. 2011;34(10): 2152-2157.

45. van Gool C, Penninx B, Kempen G, et al. Determinants of high and low attendance to diet and exercise interventions among overweight and obese older adults. Contemp Clin Trials. 2006;27(3):227-237.

46. Wang J, Sereika S, Chasens ER, Ewing LJ, Matthews JT, Burke LE. Effect of adherence to self-monitoring of diet and physical activity on weight loss in a technology-supported behavioral intervention. Patient Prefer Adherence. 2012;6:221-226.

47. Public Health Agency of Canada [webpage on the Internet]. What Makes Canadians Healthy or Unhealthy? Available from: http://www. phac-aspc.gc.ca/ph-sp/determinants/determinants-eng/php. Accessed December 7, 2015.

48. Ben-Shlomo Y, Smith GD, Shipley M, Marmot MG. Magnitude and causes of mortality differences between married and unmarried men. J Epidemiol Community Health. 1993;47(3):200-205.

49. Holt-Lunstad J, Smith TB, Layton JB. Social relationships and mortality risk: a meta-analytic review. PLoS Med. 2010;7(7):e1000316.

50. Beasley JM, Newcomb PA, Trentham-Dietz A, et al. Social networks and survival after breast cancer diagnosis. J Cancer Surviv. 2010;4(4): 372-380.

51. Brantley PJ, Stewart DW, Myers VH, et al. Psychosocial predictors of weight regain in the weight loss maintenance trial. J Behav Med. 2014; 37(6):1155-1168.

52. Wing RR, Jeffery RW. Benefits of recruiting participants with friends and increasing social support for weight loss and maintenance. $J$ Consult Clin Psychol. 1999;67(1):132-138.

53. Harris MB, Bruner CG. A comparison of a self-control and a contract procedure for weight control. Behav Res Ther. 1971;9(4):347-354.

54. Aguilar-Martinez A, Sole-Sedeno JM, Mancebo-Moreno G, Medina FX, Carreras-Collado R, Saigi-Rubio F. Use of mobile phones as a tool for weight loss: a systematic review. J Telemed Telecare. 2014;20(6): 339-349.

55. O'Shea SD, Taylor NF, Paratz JD. ...But watch out for the weather: factors affecting adherence to progressive resistance exercise for persons with COPD. J Cardiopulm Rehabil Prev. 2007;27(3):166-174.

56. Avers $\mathrm{D}$, Wharton $\mathrm{M}$. Improving exercise adherence: instructional strategies. Top Geriatr Rehabil. 1991;6:62-73. 
57. Lemstra M, Blackburn D, Crawley F, Fung F. Proportion and risk indicators of non-adherence to statin therapy: a meta-analysis. Can J Cardiol. 2012;28(5):574-580.

58. Hannan EL. Randomized clinical trials and observational studies: guidelines for assessing respective strengths and limitations. JACC. 2008;1(3):211-217.

59. Sorensen JT, Lash TL, Rothman KJ. Beyond randomized controlled trials: a critical comparison of trials with nonrandomized studies. Hepatology. 2006;44(5):1075-1082.

60. Ting HH, Sjojania KG, Montori VM, Bradley EH. Quality improvementscience and action. Circulation. 2009;119(14):1962-1974.
61. Dhurandhar NV, Schoeller D, Brown AW, et al. Energy balance measurement: when something is not better than nothing. Int J Obes. 2014; 39(7):1109-1113.

62. Mill WC, Koceja DM, Hamilton EJ. A meta-analysis of the past 25 years of weight loss research using diet, exercise, or diet plus exercise intervention. Int J Obes. 1997;21(10):941-947.

63. Kruger J, Blanck HM, Gillespie C. Dietary and physical activity behaviors among adults successful at weight loss maintenance. Int J Behav Nutr Phys Act. 2006;3:17-26. 


\section{Supplementary materials \\ Search terms}

Weight loss programs

Weight loss intervention

Weight loss regimen

Weight loss plan

Weight reduction programs

Weight reduction intervention

Weight reduction regimen

Weight reduction plan

Adherence

Behavior modification

\section{Search strategy}

(()((()((Weight loss programs) OR weight loss intervention) OR weight loss regimen) OR weight loss plan) OR weight reduction programs) $\mathrm{OR}$ weight reduction intervention) $\mathrm{OR}$ weight reduction regimen) OR weight reduction plan)) AND ((adherence) OR "behavior modification").

\section{Databases searched}

Medline

PubMed
Cochrane Library

CINAHL

Global Health

ISI Web of Knowledge

ProQuest

SCOPUS

EMBASE

\section{Inclusion criteria}

1. Article should be in English language.

2. Article should have a prospective design.

3. Article should have quantifiable data describing the effect size.

4. Article should describe participation in a supervised weight loss program that is neither pharmacologic nor surgical and assess adherence to the said program.

5. Article is publicly available.

\section{Publish your work in this journal}

Patient Preference and Adherence is an international, peer-reviewed, open access journal that focuses on the growing importance of patient preference and adherence throughout the therapeutic continuum. Patient satisfaction, acceptability, quality of life, compliance, persistence and their role in developing new therapeutic modalities and compounds to optimize clinical outcomes for existing disease states are major areas of interest for the journal. This journal has been accepted for indexing on PubMed Central The manuscript management system is completely online and includes a very quick and fair peer-review system, which is all easy to use. Visit http://www. dovepress.com/testimonials.php to read real quotes from published authors. 